Çukurova Üniversitesi Mühendislik Mimarlık Fakültesi Dergisi, 31(2), ss. 149-158, Aralık 2016

Çukurova University Journal of the Faculty of Engineering and Architecture, 31(2), pp. 149-158, December 2016

\title{
Parasetamolün İçme Sularından Koagülasyonla Giderimi ve Sıcaklığın Etkisi
}

\author{
Mesut BAŞIBÜYÜK ${ }^{1}$, Fatma Elçin ERKURT ${ }^{* 1}$ \\ ${ }^{1}$ Çukurova Üniversitesi, Mühendislik Mimarlık Fakültesi, Çevre Mühendisliği Bölümü, Adana
}

Geliş tarihi: 02.06.2016 Kabul tarihi: 23.11.2016

Öz

$\mathrm{Bu}$ çalışmada, parasetamolün içme sularından koagülasyonla giderimi, dört farklı koagülant $\left(\mathrm{FeCl}_{3} \cdot 6 \mathrm{H}_{2} \mathrm{O}\right.$, $\left.\mathrm{MgCl}_{2} \cdot 6 \mathrm{H}_{2} \mathrm{O}, \mathrm{Al}_{2}\left(\mathrm{SO}_{4}\right)_{3} \cdot 18 \mathrm{H}_{2} \mathrm{O}, \mathrm{FeSO}_{4} \cdot 7 \mathrm{H}_{2} \mathrm{O}\right)$ kullanılarak araştırılmıştır. Tüm koagülasyon deneyleri jar test analizleri kullanılarak gerçekleştirilmiş̧ir. Optimum $\mathrm{pH}$ ve koagülant dozlarının belirlenmesinden sonra sıcaklığın etkisinin incelenmesi amaciyla dört farklı sıcaklıkta $\left(10,15,20\right.$ ve $\left.25^{\circ} \mathrm{C}\right)$ koagülasyon çalışmaları yapılmıștır. Parasetamolün en yüksek giderim verimi (\%46) $\mathrm{FeCl}_{3} \cdot 6 \mathrm{H}_{2} \mathrm{O}$ ile pH 11 'de elde edilmiştir. $\mathrm{FeCl}_{3} \cdot 6 \mathrm{H}_{2} \mathrm{O}$ ile optimum değerlerde $10^{\circ} \mathrm{C}$ 'de parasetamol giderim verimi $\% 22$ iken aynı şartlarda sıcaklık $25^{\circ} \mathrm{C}$ 'ye çıkarıldığında yüzde giderim verimi $\% 53$ olarak elde edilmiştir. Tüm koagülasyon deneylerinde sıcaklığın artmasıyla yüzde giderim veriminin arttığı tespit edilmiştir.

Anahtar Kelimeler: Parasetamol, Koagülasyon, İçme suyu

\section{Removal of Paracetamol from Drinking Water by Coagulation and Effect of Temperature}

\begin{abstract}
In this study, the removal of paracetamol by using four different coagulants $\left(\mathrm{FeCl}_{3} \cdot 6 \mathrm{H}_{2} \mathrm{O}, \mathrm{MgCl}_{2} \cdot 6 \mathrm{H}_{2} \mathrm{O}\right.$, $\left.\mathrm{Al}_{2}\left(\mathrm{SO}_{4}\right)_{3} \cdot 18 \mathrm{H}_{2} \mathrm{O}, \mathrm{FeSO}_{4} \cdot 7 \mathrm{H}_{2} \mathrm{O}\right)$ from drinking water was investigated. All of the coagulation experiments were performed by using jar test. After the determination of optimum coagulant dosage and $\mathrm{pH}$, coagulation experiments were performed at four different temperatures to detemine the effect of temperature. The highest removal efficiency of paracetamol was obtained with $\mathrm{FeCl}_{3} \cdot 6 \mathrm{H}_{2} \mathrm{O}$ and at $\mathrm{pH} 11$. While paracetamol removal efficiency was determined $22 \%$ with $\mathrm{FeCl}_{3} \cdot 6 \mathrm{H}_{2} \mathrm{O}$ under optimum conditions, at $10^{\circ} \mathrm{C}$, it was removed with $53 \%$ efficiency at $25^{\circ} \mathrm{C}$ under same conditions. It was determined that the removal efficiency increased with increasing temperature for all coagulation experiments.
\end{abstract}

Keywords: Paracetamol, Coagulation, Drinking water

\footnotetext{
*Sorumlu yazar (Corresponding author): Fatma Elçin ERKURT, eerkurt@cu.edu.tr
} 


\section{GíRiş}

Farmasötiklerin günümüzde insan kullanımı ve veteriner amaçlı kullanımının giderek yaygınlaşıp, artması neticesinde kirleticiler arasında önemli ve acil önlem alınması gereken gruplar arasına girmiştir. Farmasötik olarak aktif olan bileşikler (FAM), insan ve hayvanlarda görülebilen bir takım hastalıkların, düzensizliklerin, anormal fiziksel durumların veya bunların semptomlarının teşhisi, tedavisi, hafifletilmesi amacı ile üretilen bir veya birkaç etken madde karışımını ihtiva edebilen bileşiklerdir [1]. Farmasötik terimi geniş bir aralık sınıfında, değişken yapıda, fonksiyonda, davranışta ve aktivitede bileşikleri kapsar [2].

Farmasötikler karaciğer, bağırsak, böbrek, akciğer gibi vücut dokularında bir takım enzimatik transformasyonlara uğrarlar. Vücut kendisine yabancı olan bu maddeleri gidermek ve detoksifikasyon amaciyla metabolize ederek tepki verir. Metabolizmanın önemli bir kısmı karaciğerde gerçekleşir. Her ilaç vücutta, etken maddenin bir kısım veya tüm farmasötik aktivitesini giderecek şekilde farklı seviyelerde daha polar metabolitlerine dönüştürülür. Farmasötiklerin sucul ortamlara geçişindeki en yaygın yol insani tüketim neticesinde vücut tarafından kanalizasyon sistemine atılması buradan atıksu arıtma tesislerine ve neticede yüzey sularına ulaşmasıdır. FAM'ların vücuttan atılması neticesinde bu kimyasal maddeler veya onların vücut içerisinde oluşan metabolit ürünleri idrar ve dışkı yoluyla su ortamına karışabilmektedir. FAM'lar bu yüzden toprakta, yüzey sularında, dip çamurlarında, evsel atıksularda, arıtma çamurlarında ve yer altı sularında tespit edilmektedir [3]. Farmasötiklerin vücut tarafindan metabolize edilmesi farmasötik türüne göre değişiklik göstermektedir. Örneğin Karbamazepin $\% 97$ metabolize olurken bir antibiyotik olan amoksilin \%80-90 arasında vücuttan ana formda atılmaktadır [4]. Kullanıma hazır içme sularında FAM'ların mevcudiyetini bildiren sınırlı sayıda çalışma vardır. $\mathrm{Bu}$ durum içme sularında bulanabilecek FAM'ların çok düşük ng/L mertebelerinde olmasından dolayı oluşan analitik zorluklardan kaynaklanmaktadir. $\mathrm{Bu}$ konsantrasyonlar çoğu zaman tespit limitlerinin altında kalabilmektedir. Musluk sularında FAM'ların bu kadar düşük konsantrasyonda bulunmaları, bu konuyu önemsiz bir duruma getireceği asla düşünülmemelidir. Sıradan bir insanın günde 2 litre su içtiği farz edilirse kalıntı şeklinde alınması mümkün olan ilaç miktarları tedavi amaçlı alınan miktarların çok altında kalmaktadır. Ancak bu kalıntı miktarlarının sürekli alınması ayrıca bir ilaç kokteyli şeklinde alınması da önem arz etmektedir. Burada etken maddelerin birbirleriyle sinerjistik etki sergilemesi söz konusu olabilmektedir. Ayrıca bu durum yetişkinlerin yanında bebek ve çocuklarda daha büyük önem arz etmektedir. FAM'ların içme sularında mevcudiyetinin en önemli nedeni su kaynağında bulunan FAM'ların geleneksel içme suyu arıtma proseslerine karşı dirençli olmasından kaynaklanmaktadır. $\mathrm{Bu}$ kimyasallar genellikle; yüksek kimyasal kararlılığa, düşük biyolojik indirgenmeye, suda yüksek oranda çözünme ve düşük sorpsiyon katsayılarına sahiptirler [5].

Koagülasyon içme sularında doğal organik maddelerin ve bulanıklılığın giderilmesinde etkili bir yöntem olmasından dolayı yaygın kullanılan bir işlemdir [6]. Literatürde yapılan bazı çalışmaların sonucuna göre içme sularında koagülasyon ile ilaçların giderim verimleri genellikle düşük kalmıştır [7,8,9]. Bu durum büyük olasılıkla ilaçların genellikle düşük hidrofobikliği ve flok içine adsorbe olacak mekanizmanın eksikliğinden kaynaklanmaktadır [7].

Çoğu analjezikler (ağrı kesiciler) anti-inflamatuar ve antipiretik özelliklere sahiptir. Pek çok ağr1 kesici ilaç grupları pek çok ülkede çok miktarlarda kullanılıp aynı zamanda reçetesiz olarak satılmaktadır. Parasetamol ve asetilsalisilik asit dünyada en yaygın kullanılan ağrı kesicilerdir. Almanya'da 2001 y1lında y1llık asetilsalisilik asit satışı 500 tonun üzerinde olarak hesaplanmıştır. Bunu yanında yine Almanya'da diğer ağrı kesicilerden ibuprofen veya diklofenağın yıllık satış miktarları yaklaşık olarak 75 ve 180 ton olarak hesaplanmıştır. Ternes 1998 'de yaptığ 1 çalışmasında Asetilsalisilik asit konsantrasyonunun 
Almanya atıksu arıtma tesisi çıkış sularında yaklaşık olarak 0,22 $\mu \mathrm{g} / \mathrm{L}$ olarak saptamıştır [10].

Parasetamol (asetaminofen), ağrı kesici ve ateş düşürücü etkiye sahip bir ilaç etken maddesidir. Günümüzde analjezik ve antipiretik amaçlı en sık kullanılan ilaçlardan biri olan parasetamol (asetaminofen; para-asetil-amino-fenol) ilk kez 1878 yılında sentezlenmiş, ve 1893 yılında tıbbi kullanıma girmiştir [11,12]. Parasetamol özellikle çocuk, yaşlı, gebe gibi özel gruplar başta olmak üzere tıbbi kullanımdaki en güvenilir analjezik/antipiretik ilaçlardan biri olarak kabul edilmektedir ve günümüzde tüm dünyada milyonlarca hasta tarafindan kullanılmaktadır [13].

\section{MATERYAL VE METOT}

\subsection{Materyal}

\subsubsection{Kullanılan İlaç ve Koagülantlar}

Çalışmada yaygın olarak kullanılan bir ilaç etken maddesi olan parasetamol kullanılmıştır. Parasetamol (Asetominofen) Sigma firmasından temin edilmiştir. Parasetamolün bazı özellikleri Çizelge 1'de verilmiştir.

Çizelge 1. Parasetamolün bazı özellikleri

\begin{tabular}{|l|c|}
\hline & \\
\hline Kimyasal yapısı & $103-90-2$ \\
\hline Kimyasal formül & $151,2 \mathrm{~g} / \mathrm{mol}$ \\
\hline CAS No & 0,46 \\
\hline Molekül Ağırlı̆̆ & 9,4 \\
\hline Log K & $\mathrm{C}_{\text {ow }} \mathrm{H}_{9} \mathrm{NO}_{2}$ \\
\hline pK & \\
\hline Diğer isimler & Acetaminophen, N-(4- \\
\hline Erime Noktası & $170{ }^{\circ} \mathrm{C}\left(338^{\circ} \mathrm{F}\right)$ \\
\hline Toksisite & $\mathrm{LD} 50: 338 \mathrm{mg} / \mathrm{kg}($ fare $)$ \\
\hline Yoğunluk & $1,3 \mathrm{~g} / \mathrm{cm}^{3}$ \\
\hline
\end{tabular}

Gerek endüstriyel atıksuların arıtılmasında ve gerekse içme suyu arıtımında yaygın olarak kullanılan koagülantlar seçilmiştir. Çalışmada kullanılan koagülantlar Merck firmasından temin edilmiştir. Kullanılan koagülantlar, kimyasal formülleri ve molekül ağırlıkları Çizelge 2'de verilmiştir.

Çizelge 2. Çalışmada kullanılan koagülantlar

\begin{tabular}{|c|c|c|}
\hline $\begin{array}{c}\text { Koagülant } \\
\text { madde }\end{array}$ & $\begin{array}{c}\text { Kimyasal } \\
\text { formüllü }\end{array}$ & $\begin{array}{c}\text { Mol. } \\
\text { ağırlığı } \\
\text { (g/mol) }\end{array}$ \\
\hline $\begin{array}{c}\text { Alüminyum } \\
\text { sülfat }\end{array}$ & $\mathrm{Al}_{2}\left(\mathrm{SO}_{4}\right)_{3} \cdot 18 \mathrm{H}_{2} \mathrm{O}$ & 666,42 \\
\hline $\begin{array}{c}\text { Demir III } \\
\text { Klorür }\end{array}$ & $\mathrm{FeCl}_{3} \cdot 6 \mathrm{H}_{2} \mathrm{O}$ & 270,33 \\
\hline Demir II Sülfat & $\mathrm{FeSO}_{4} \cdot 7 \mathrm{H}_{2} \mathrm{O}$ & 278,02 \\
\hline $\begin{array}{c}\text { Magnezyum } \\
\text { Klorür }\end{array}$ & $\mathrm{MgCl}_{2} \cdot 6 \mathrm{H}_{2} \mathrm{O}$ & 203,30 \\
\hline
\end{tabular}

\subsection{Metod}

\subsubsection{Jar Test Analizi}

Jar test deneyleri, rpm ayarlı, 6'lı jar test düzeneğinde gerçekleştirilmiştir. Jar testi deneylerinde giderimi araştırılan ilaç etken maddesinin her bir koagülant için optimum çalışma şartları belirlenmiştir. Yapılan tüm jar testleri, 100 rpm'de $1 \mathrm{dk}$ hızlı karıștırma, 30 rpm'de $30 \mathrm{dk}$ yavaş karıştırma ve $30 \mathrm{dk}$ çökelme işlemleri sırasıyla gerçekleştirilmiştir. Çalışmanın birinci aşamasında kullanılan her koagülant için optimum $\mathrm{pH}$ değeri belirlenmiştir. Bu aşamada ilaç konsantrasyonu $5 \mathrm{mg} / \mathrm{L}$ ve koagülant konsantrasyonlar1 $100 \mathrm{mg} / \mathrm{L}$ olarak sabit tutularak farklı $\mathrm{pH}$ değerlerinde $(3,4,5,6,7,8,9,10,11$, 12) ilaç giderimi çalışılmıştır. Çalışmanın ikinci aşamasından her koagülant için ayrı ayrı belirlenmiş olan optimum $\mathrm{pH}$ değerlerinde optimum koagülant dozu belirleme deneyleri gerçekleştirilmiştir. $\mathrm{Bu}$ aşamada ilaç konsantrasyonu $5 \mathrm{mg} / \mathrm{L}$ 'de sabit tutularak farklı koagülant dozları denenmiştir $(10,25,50,75,100$, 125, 150, $175 \mathrm{mg} / \mathrm{L})$. Daha sonra $5 \mathrm{mg} / \mathrm{L}$ ilaç konsantrasyonu için optimum koagülant dozu ve optimum $\mathrm{pH}$ değerlerinde, ilaç giderimi üzerine sıcaklığın etkisini araştırmak için farklı sıcaklık 
değerleri $\left(10,15,20\right.$ ve $\left.25^{\circ} \mathrm{C}\right)$ çalışılmıştır. Sıcaklık ayarlaması su ceketi ile sağlanmıştır. Çalışmada kullanılan jar test düzeneği Şekil 1'de gösterilmiştir.

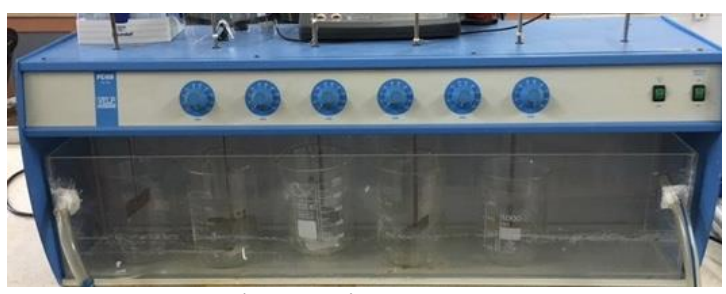

Şekil 1. Jar test düzeneği

\subsection{2. İlaç Etken Madde Ölçümleri}

Çalışmada ilaç etken maddesinin (parasetamol) ölçümü UV detektöre sahip Perkin Elmer marka HPLC'de (yüksek basınçlı sıvı kromotografisi) yapılmıştır. Parasetamol için dalga boyu taraması yapılmış maksimum adsorbans veren dalga boyu seçilmiş ve literatüre uygunluğu kontrol edilmiştir.

\subsubsection{Katı Faz Ayırma Metodu}

HPLC'de analiz öncesi örneklerde katı faz ekstraksiyon teknikleri kullanılarak örnek hazırlama basamağı gerçekleştirilmektedir. Katı faz ekstraksiyonunu kullanmamizın nedeni örneklerin istenmeyen bileşiklerden temizlenmesi ve yoğunlaştırılmasıdır. Temizleme işlemi ile analizin yanlış sonuçlanmasına neden olabilecek, aranan maddenin tespit edilmesini engelleyebilecek veya analiz cihazının kirlenmesine neden olabilecek kirliliklerin uzaklaştırılması sağlamaktır. Numunelerdeki yoğunlaştırma işlemi ise atıksudaki ilaç konsantrasyonlarının HPLC/UV sisteminde doğrudan tespitini mümkün kılmayacak düşük seviyelerde olmasından kaynaklanmaktadır.

Katı faz ekstraksiyonu (solid phase extraction, SPE) yöntemi, sıv1-sıv1 ekstraksiyon (liquid-liquid extraction, (LLE) yöntemine göre; daha kısa sürede uygulanabilmesi ve daha yüksek geri kazanım oranına sahip olmasından dolayı tercih edilmiştir. HPLC analizlerinden önce numuneler
Oasis HLB 3 cc 60 mg SPE kartuşu kullanılarak ekstrakte edilmekte, böylece analizlerde girişim yapacak diğer organik bileşiklerden ve kolonu tıkayabilecek inorganik iyonlardan arındırılmaktadır. Numuneler $1 \mathrm{~N}$ hidroklorik asit (HCL) ile $\mathrm{pH}=2$ 'ye ayarlanmıştır. Seçilen farmasötik bileşikler asidik olduklarından atıksu numunelerinin pH'ını düşürmek bu maddelerin ekstraksiyon kartuşu üzerinde daha fazla tutunmasını sağlayarak geri kazanımını artırır. Yapılan çalışmalarda asidik ilaçların katı faz ekstraksiyonunda en iyi geri kazanımı $\mathrm{pH}=2$ 'de sağlanmıştır $[14,15]$.

\section{BULGULAR VE TARTIŞMA}

\section{1. $\mathrm{FeSO}_{4} \cdot 7 \mathrm{H}_{2} \mathrm{O}$ Koagülasyonu ile Parasetamol Gideriminin İncelenmesi}

\subsubsection{Optimum pH'ın Belirlenmesi}

Koagülant olarak $\mathrm{FeSO}_{4} .7 \mathrm{H}_{2} \mathrm{O}$ kullanılarak yapılan optimum $\mathrm{pH}$ belirleme çalışmasında 10 farklı $\mathrm{pH}$ değerinde $(3,4,5,6,7,8,9,10,11,12) 100 \mathrm{mg} / \mathrm{L}$ koagülant dozu ve $5 \mathrm{mg} / \mathrm{L}$ ilaç konsantrasyonunda jar test deneyleri yapılmıştır. En yüksek parasetamol yüzde giderim oranı $\mathrm{pH}$ 5'de \%37,8 olarak elde edilmiştir. Tüm $\mathrm{pH}$ değerlerinde elde edilen yüzde giderim oranları şekil 2'deki grafikte gösterilmiştir.

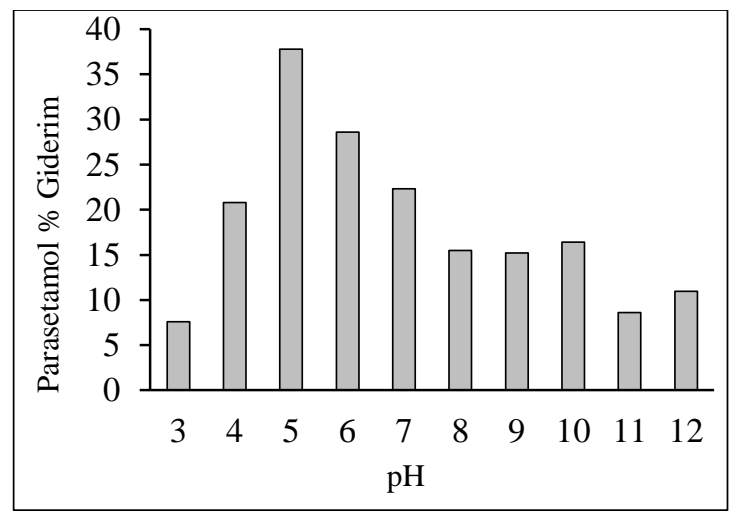

Şekil 2. $\mathrm{FeSO}_{4} \cdot 7 \mathrm{H}_{2} \mathrm{O}$ ile koagülasyonda farklı $\mathrm{pH}$ değerlerinde parasetamol yüzde giderim oranlar1 


\subsubsection{Optimum Koagülant Dozunun Belirlenmesi}

Belirlenen optimum $\mathrm{pH}$ değerinde (5), $5 \mathrm{mg} / \mathrm{L}$ ilaç konsantrasyonu ve $20^{\circ} \mathrm{C}$ 'de, 7 farkl $1 \mathrm{FeSO}_{4} \cdot 7 \mathrm{H}_{2} \mathrm{O}$ koagülant dozu $(10,25,50,75,100,125$, $150 \mathrm{mg} / \mathrm{L})$ denenmiştir. Yapılan çalışma sonucunda optimum koagülant dozu olarak 100 $\mathrm{mg} / \mathrm{L}$ seçilmiştir. $100 \mathrm{mg} / \mathrm{L}$ koagülant dozunda parasetamol yüzde giderim oranı \% 37,8 olarak hesaplanmıştır. Yapılan çalışma sonucu elde edilen yüzde giderim değerleri Şekil 3'de verildiği gibidir.

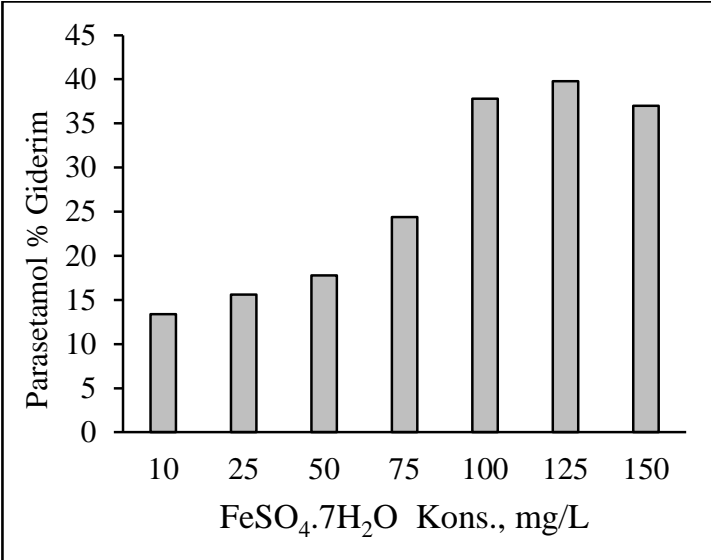

Şekil.3. Farklı $\mathrm{FeSO}_{4} \cdot 7 \mathrm{H}_{2} \mathrm{O}$ koagülantı dozlarında parasetamol yüzde giderim oranları

\subsection{3. $\mathrm{FeSO}_{4} \cdot 7 \mathrm{H}_{2} \mathrm{O}$ Koagülasyonu ile Parasetamol Gideriminde Sıcaklığın Etkisi}

$\mathrm{FeSO}_{4} \cdot 7 \mathrm{H}_{2} \mathrm{O}$ ile koagülasyonda parasetamol giderimine sıcaklığın etkisini araştırmak amacıyla 4 farklı sıcaklık değeri $\left(10,15,20\right.$ ve $\left.25^{\circ} \mathrm{C}\right)$ jar test düzeneğine uygulanarak incelenmiştir. Sicaklığın artmasıyla giderim yüzdesinin arttığı gözlenmiştir. 4 farklı sicaklık değerindeki yüzde giderimler Şekil 4'te grafik olarak gösterilmiştir.

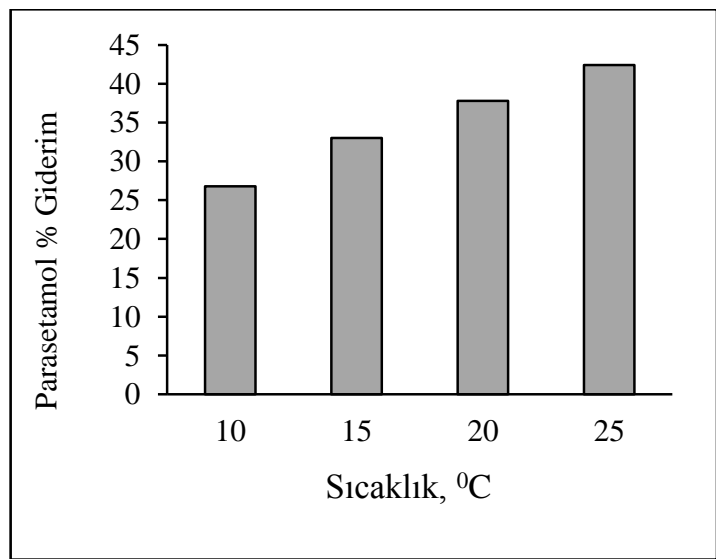

Şekil 4. $\mathrm{FeSO}_{4} \cdot 7 \mathrm{H}_{2} \mathrm{O}$ ile koagülasyonda farklı sıcaklık değerlerindeki parasetamol yüzde giderim oranları

\section{2. $\mathrm{FeCl}_{3} \cdot 6 \mathrm{H}_{2} \mathrm{O}$ Koagülasyonu ile Parasetamol Gideriminin İncelenmesi}

\subsubsection{Optimum pH'ın Belirlenmesi}

Koagülant olarak $\mathrm{FeCl}_{3} \cdot 6 \mathrm{H}_{2} \mathrm{O}$ kullanılarak yapılan optimum $\mathrm{pH}$ belirleme çalışmasında 10 farklı $\mathrm{pH}$ değerinde $(3,4,5,6,7,8,9,10,11,12) 100 \mathrm{mg} / \mathrm{L}$ koagülant dozu ve $5 \mathrm{mg} / \mathrm{L}$ ilaç konsantrasyonunda jar test deneyleri yapılmıştır. En yüksek parasetamol yüzde giderim oranı $\mathrm{pH} \mathrm{11}$ 'de \%46 olarak elde edilmiştir. Tüm $\mathrm{pH}$ değerlerinde elde edilen yüzde giderim oranları Şekil 5'teki grafikte gösterilmiştir.

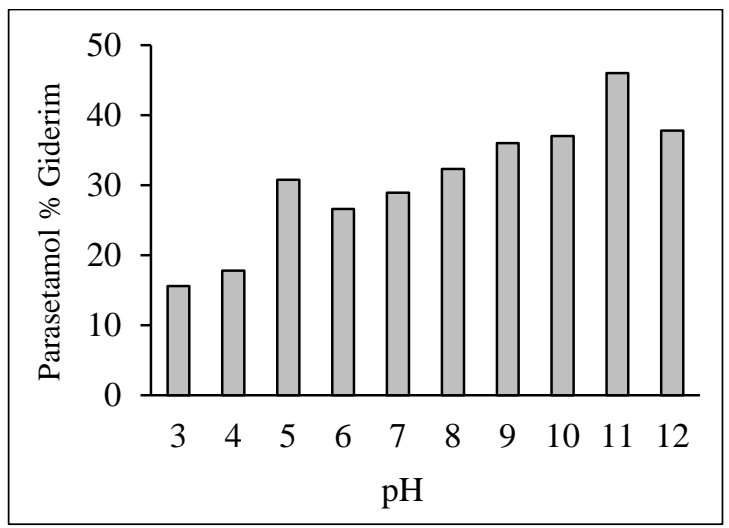

Şekil 5. $\mathrm{FeCl}_{3} \cdot 6 \mathrm{H}_{2} \mathrm{O}$ koagülantı ile farklı $\mathrm{pH}$ değerlerinde parasetamol yüzde giderim oranlar1 


\subsubsection{Optimum Koagülant Dozunun Belirlenmesi}

Belirlenen optimum $\mathrm{pH}$ değerinde (11), $5 \mathrm{mg} / \mathrm{L}$ ilaç konsantrasyonu ve $20^{\circ} \mathrm{C}$ 'de, 7 farkl $\mathrm{FeCl}_{3} .6 \mathrm{H}_{2} \mathrm{O}$ koagülant dozu $(10,25,50,75,100$, $125,150 \mathrm{mg} / \mathrm{L}$ ) denenmiştir. Yapılan çalışma sonucunda optimum koagülant dozu olarak $100 \mathrm{mg} / \mathrm{L}$ seçilmiştir. $100 \mathrm{mg} / \mathrm{L}$ koagülant dozunda parasetamol yüzde giderim oranı $\% 46$ olarak hesaplanmıştır. Uygulanan koagülant dozları ve yüzde giderim oranları Şekil 6'daki grafikte gösterilmiştir.

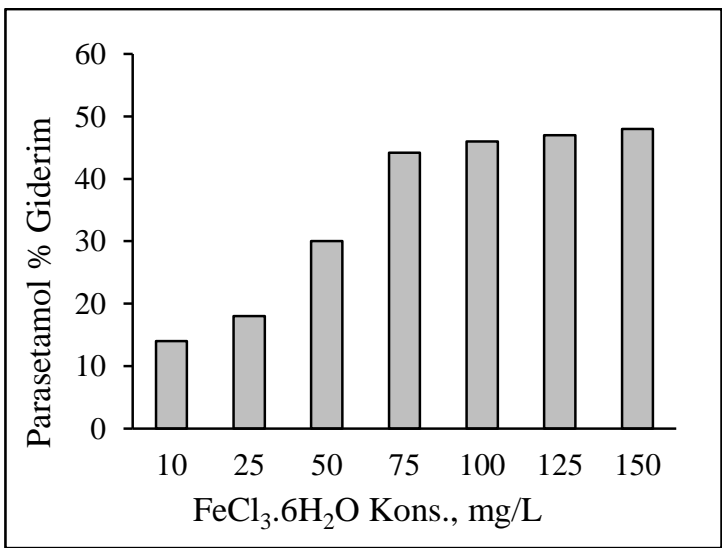

Şekil 6. Farklı $\mathrm{FeCl}_{3} \cdot 6 \mathrm{H}_{2} \mathrm{O}$ koagülantı dozlarında parasetamol yüzde giderim oranları

\subsection{3. $\mathrm{FeCl}_{3} \cdot 6 \mathrm{H}_{2} \mathrm{O}$ Koagülasyonu ile Parasetamol Gideriminde Sıcaklığın Etkisi}

$\mathrm{FeCl}_{3} \cdot 6 \mathrm{H}_{2} \mathrm{O}$ ile koagülasyonda parasetamol giderimine sıcaklığın etkisini araştırmak amacıyla 4 farklı sıcaklık değeri $\left(10,15,20\right.$ ve $\left.25^{\circ} \mathrm{C}\right)$ jar test düzeneğine uygulanarak incelenmiştir. Sicaklığın artmasıyla giderim yüzdesinin arttığı gözlenmiştir. 4 farklı sıcaklık değerindeki yüzde giderimler Şekil 7'deki grafikte gösterilmiştir.

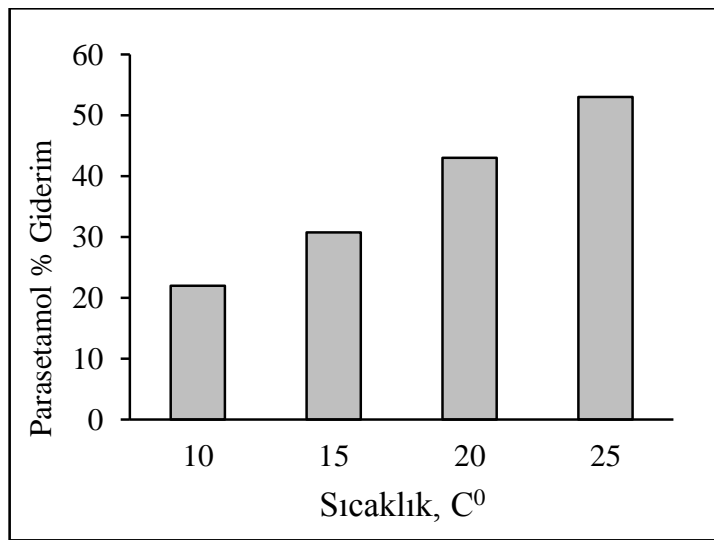

Şekil 7. $\mathrm{FeCl}_{3} \cdot 6 \mathrm{H}_{2} \mathrm{O}$ ile koagülasyonda farkl sıcaklık değerlerindeki parasetamol yüzde giderim oranları

\section{3. $\mathrm{Al}_{2}\left(\mathrm{SO}_{4}\right)_{3} \cdot 18 \mathrm{H}_{2} \mathrm{O}$ Koagülasyonu ile Parasetamol Gideriminin İncelenmesi}

\subsubsection{Optimum pH'ın Belirlenmesi}

Koagülant olarak $\mathrm{Al}_{2}\left(\mathrm{SO}_{4}\right)_{3} \cdot 18 \mathrm{H}_{2} \mathrm{O}$ kullanılarak yapılan optimum $\mathrm{pH}$ belirleme çalışmasında $20 \mathrm{C}^{\circ}$ 'de, $100 \mathrm{mg} / \mathrm{L}$ koagülant dozu ve $5 \mathrm{mg} / \mathrm{L}$ ilaç konsantrasyonunda 10 farklı $\mathrm{pH}$ değeri $(3,4,5,6$, $7,8,9,10,11,12)$ için jar test deneyleri yapılmıştır. En yüksek parasetamol yüzde giderim oranı $\mathrm{pH}$ 7'de \%30 olarak elde edilmiştir. Tüm $\mathrm{pH}$ değerlerinde elde edilen yüzde giderim oranları Şekil 8'deki grafikte gösterilmiştir.

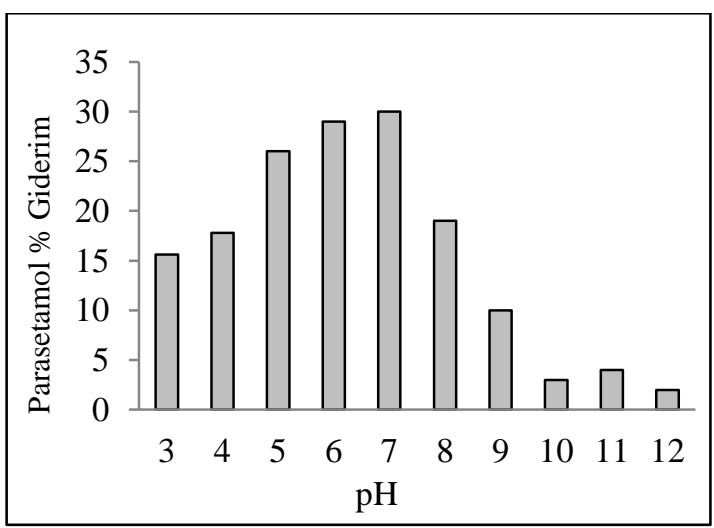

Şekil 8. $\mathrm{Al}_{2}\left(\mathrm{SO}_{4}\right)_{3} \cdot 18 \mathrm{H}_{2} \mathrm{O}$ koagülantı ile farklı $\mathrm{pH}$ değerlerinde parasetamol yüzde giderim oranları 


\subsubsection{Optimum Koagülant Dozunun Belirlenmesi}

Belirlenen optimum $\mathrm{pH}$ değerinde (7), $5 \mathrm{mg} / \mathrm{L}$ ilaç konsantrasyonu ve $20^{\circ} \mathrm{C}^{\prime} \mathrm{de}, \quad 7$ farkl 1 $\mathrm{Al}_{2}\left(\mathrm{SO}_{4}\right)_{3} .18 \mathrm{H}_{2} \mathrm{O}$ koagülant dozu $(10,25,50,75$, $100,125,150 \mathrm{mg} / \mathrm{L})$ denenmiştir. Yapılan çalışma sonucunda optimum koagülant dozu olarak 100 $\mathrm{mg} / \mathrm{L}$ seçilmiştir. $100 \mathrm{mg} / \mathrm{L}$ koagülant dozunda parasetamol yüzde giderim oranı $\% 30$ olarak hesaplanmıştır. Uygulanan koagülant dozları ve yüzde giderim oranları Şekil 9'daki grafikte gösterilmiştir.

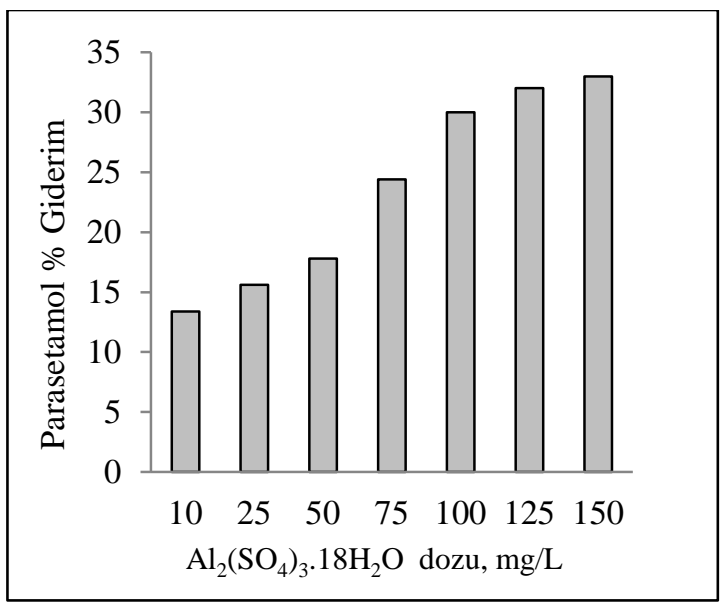

Şekil 9. Farklı $\mathrm{Al}_{2}\left(\mathrm{SO}_{4}\right)_{3} \cdot 18 \mathrm{H}_{2} \mathrm{O} \quad$ koagülantı dozlarında parasetamol yüzde giderim oranlar1

\subsection{3. $\mathrm{Al}_{2}\left(\mathrm{SO}_{4}\right)_{3} .18 \mathrm{H}_{2} \mathrm{O}$ Koagülasyonu ile Parasetamol Gideriminde Sıcaklığın Etkisi}

$\mathrm{Al}_{2}\left(\mathrm{SO}_{4}\right)_{3} \cdot 18 \mathrm{H}_{2} \mathrm{O}$ ile koagülasyonda parasetamol giderimine sıcaklığın etkisini araştırmak amacıyla 4 farklı sıcaklık değeri $\left(10,15,20\right.$ ve $\left.25^{\circ} \mathrm{C}\right)$ jar test düzeneğine uygulanarak incelenmiştir. Sicaklığın artmasıyla giderim yüzdesinin arttığ gözlenmiştir. 4 farklı sicaklık değerindeki yüzde giderimler Şekil 10'daki grafikte gösterilmiştir.

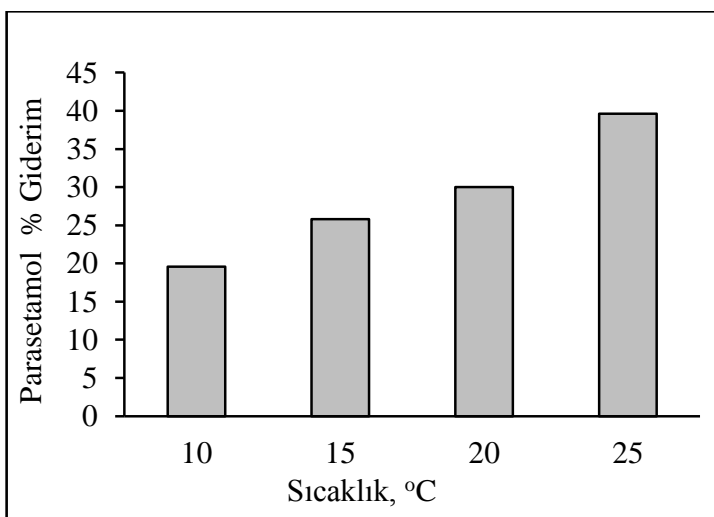

Şekil 10. $\mathrm{Al}_{2}\left(\mathrm{SO}_{4}\right)_{3} .18 \mathrm{H}_{2} \mathrm{O}$ ile koagülasyonda farklı sıcaklık değerlerindeki parasetamol yüzde giderim oranları

\section{4. $\mathrm{MgCl}_{2} \cdot 6 \mathrm{H}_{2} \mathrm{O}$ Koagülasyonu ile Parasetamol Gideriminin İncelenmesi}

\subsubsection{Optimum pH'ın Belirlenmesi}

Koagülant olarak $\mathrm{MgCl}_{2} \cdot 6 \mathrm{H}_{2} \mathrm{O}$ kullanılarak yapılan optimum $\mathrm{pH}$ belirleme çalışmasında $20 \mathrm{C}^{\circ}$ de, $100 \mathrm{mg} / \mathrm{L}$ koagülant dozu ve $5 \mathrm{mg} / \mathrm{L}$ ilaç konsantrasyonunda 10 farklı $\mathrm{pH}$ değeri $(3,4,5,6$, $7,8,9,10,11,12)$ için jar test deneyleri yapılmıştır. En yüksek parasetamol yüzde giderim oranı pH 11'de \%41 olarak elde edilmiştir. Tüm $\mathrm{pH}$ değerlerinde elde edilen yüzde giderim oranları Şekil 11'deki grafikte gösterilmiştir.

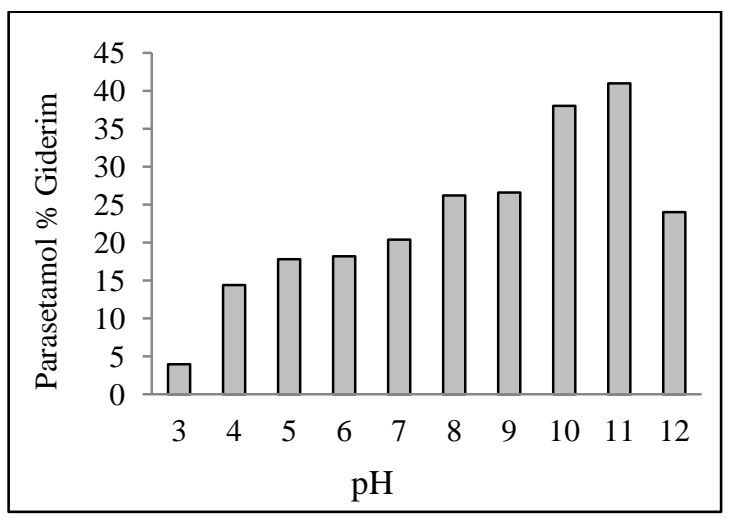

Şekil 11. $\mathrm{MgCl}_{2} \cdot 6 \mathrm{H}_{2} \mathrm{O}$ koagülantı ile farklı $\mathrm{pH}$ değerlerinde parasetamol yüzde giderim oranlar1 


\subsubsection{Optimum Koagülant Dozunun Belirlenmesi}

Belirlenen optimum $\mathrm{pH}$ değerinde (11), $5 \mathrm{mg} / \mathrm{L}$ ilaç konsantrasyonu ve $20^{\circ} \mathrm{C}$ 'de, 7 farkl 1 $\mathrm{MgCl}_{2} \cdot 6 \mathrm{H}_{2} \mathrm{O}$ koagülant dozu (10, 25, 50, 75, 100, $125,150 \mathrm{mg} / \mathrm{L}$ ) denenmiştir. Yapılan çalışma sonucunda optimum koagülant dozu olarak 100 $\mathrm{mg} / \mathrm{L}$ seçilmiştir. $100 \mathrm{mg} / \mathrm{L}$ koagülant dozunda parasetamol yüzde giderim oranı $\% 41$ olarak hesaplanmıştır. Uygulanan koagülant dozları ve yüzde giderim oranları Şekil 12'deki grafikte gösterilmiş̧tir.

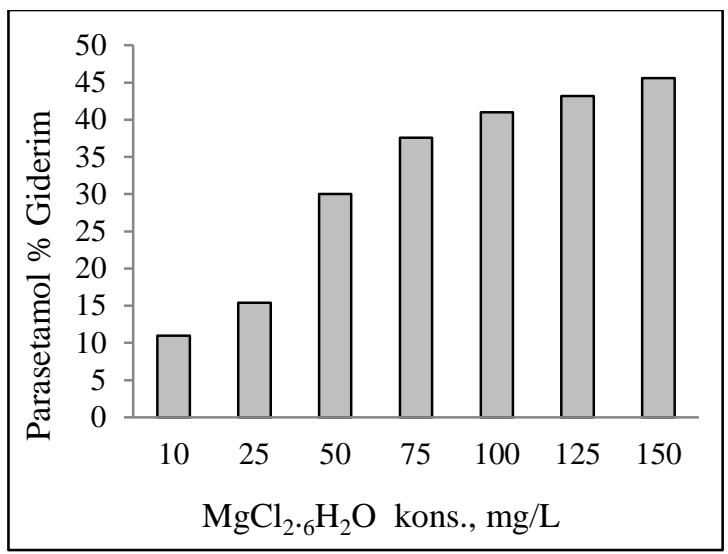

Sekil 12. Farkl1 $\mathrm{MgCl}_{2} \cdot 6 \mathrm{H}_{2} \mathrm{O}$ koagülantı dozlarında parasetamol yüzde giderim oranları

\subsection{3. $\mathrm{MgCl}_{2} \cdot 6 \mathrm{H}_{2} \mathrm{O}$ Koagülasyonu ile Parasetamol Gideriminde Sıcaklığın Etkisi}

$\mathrm{MgCl}_{2} \cdot 6 \mathrm{H}_{2} \mathrm{O}$ ile koagülasyonda parasetamol giderimine sıcaklığın etkisini araştırmak amacıyla 4 farklı sicaklık değeri $\left(10,15,20\right.$ ve $\left.25^{\circ} \mathrm{C}\right)$ jar test düzeneğine uygulanarak incelenmiştir. Sicaklığın artmasıyla giderim yüzdesinin arttığı gözlenmiştir. 4 farklı sıcaklık değerindeki yüzde giderimler Şekil 13'deki grafikte gösterilmiştir.

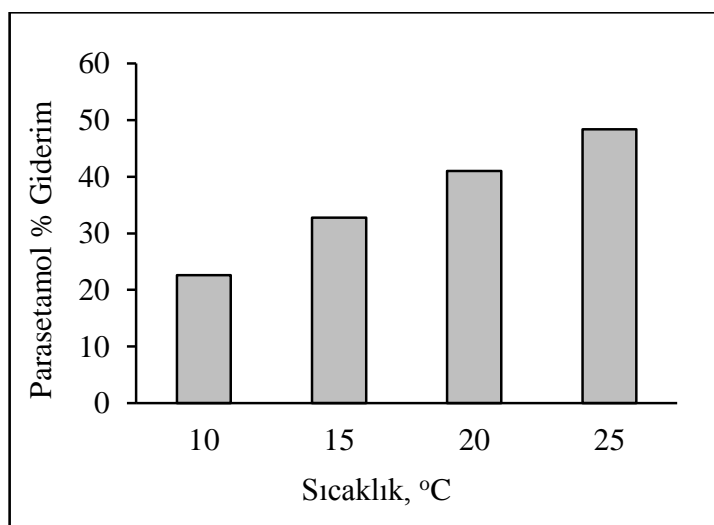

Şekil 13. $\mathrm{MgCl}_{2} \cdot 6 \mathrm{H}_{2} \mathrm{O}$ ile koagülasyonda farkl sıcaklık değerlerindeki parasetamol yüzde giderim oranları

\section{SONUÇ VE ÖNERILLER}

Parasetamol ilaç etken maddesinin 4 farklı koagülant için optimum $\mathrm{pH}$ ve dozajları belirlenmiştir. Elde edilen sonuçların karşılaştırabilmesi amacıyla koagülant madde bazında değerlerin grafiksel gösterimi yapılmıştır. Parasetamol ilaç etken maddesinin 4 farklı koagülant için elde edilen optimum $\mathrm{pH}$ ve dozda giderim verimleri Şekil 14'deki grafikte gösterilmiştir. $\mathrm{MgCl}_{2} \cdot 6 \mathrm{H}_{2} \mathrm{O}$ ve $\mathrm{FeCl}_{3} \cdot 6 \mathrm{H}_{2} \mathrm{O}$ ile koagülasyonda optimum giderim oranına $\mathrm{pH} 11$ 'de ulaşılmıştır. Parasetamolün farklı koagülantlar ile gideriminde en yüksek giderim verimi $\mathrm{FeCl}_{3} \cdot 6 \mathrm{H}_{2} \mathrm{O}$ ile \%46 olarak elde edilmiştir.

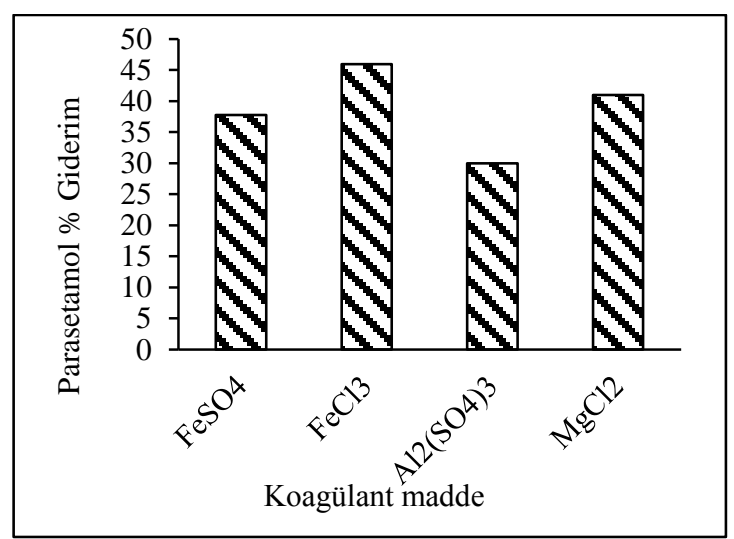

Şekil 14. Parasetamolün 4 farklı koagülant madde ile optimum şartlarda yüzde giderim verim değerleri 
Son yıllarda oktanol/su ayrıştırma katsayısı $\left(\mathrm{K}_{\mathrm{ow}}\right)$ olarak adlandırılan organik kimyasalların çevresel ortamlardaki akıbetleri konusunda yapılan çalışmalarda anahtar parametre haline gelmiştir. $\mathrm{K}_{\mathrm{ow}}$ değeri, bir maddenin iki fazındaki (n-oktanol ve su fazı) ayrışma katsayısını karakterize etmektedir [16]. Ayrıca, farmasötiklerin sudan giderilmesinde hidrofobik ve hidrofilik özellikleri önem taşımaktadır [7].

Parasetamol koagülasyon çalışmalarında dört farklı koagülant için dört farklı sıcaklık değerinde yüzde giderim verimleri incelenmiş olup sıcaklığın artmasiyla giderim verimlerinin $\operatorname{artt1\breve {g}_{1}}$ görülmüştür. Xiao ve arkadaşları düşük sıcaklığın yumaklaşma oranına olumsuz etki ettiğini bildirmişlerdir [17]. Ayrıca Guan ve arkadaşları yaptığı çalışmada sıcaklığın artması ile bulanıklık gideriminin arttığını görmüşlerdir [18]. Bu çalışmada parasetamol giderim veriminin sıcaklık artışıyla artmasının, flok yapısının artmasından ve büyümesinden kaynaklandığı düşünülmektedir.

\section{KAYNAKLAR}

1. Bila, D.M., Dezotti, M., 2003. Pharmaceuticals Drugs in the Environment. Quim. Nova, 26:523-530.

2. Derksen, J.G.M., Rijs, G.B.J., Jongbloed, R.H., 2004. Diffuse Pollution of Surface Water by Pharmaceutical Products. Water Sci. Technol, 49:213-221.

3. Halling-Sorensen, B., Nors Nielsen, S., Lanzky, P.F., Ingerslev, F., Lutzhoft, H.C., Jorgensen, S.E., 1998. Occurrence, Fate and Effects of Pharmaceutical Substances in the Environment a Review. Chemosphere, 36: 357-93.

4. Bound, J.P., Voulvoulis, N., 2004. Pharmaceuticals in The Aquatic Environment A Comparison of Risk Assessment Strategies. Chemosphere, 56: 1143-1155.

5. Zwiener, C., 2007. Occurrence and Analysis of Pharmaceuticals and Their Transformation Products in Drinking Water Treatment. Anal Bioanal Chem., 387: 1159-1162.

6. Matılainen, A., Lindqvist, N., Korhonen, S., Tuhkanen, T., 2002. Removal of Nom in The
Different Stages of the Water Treatment Process. Environment International, 28(6): 457-465.

7. Westerhoff, P., Yoon, Y., Snyder, S. Wert, E., 2005. Fate of Endocrine-Disruptor, Pharmaceutical, and Personal Care Product Chemicals During Simulated Drinking Water Treatment Processes, Environmental Science And Technology, 39(17): 6649-6663.

8. Boyd, G.R., Reemtsma, H., Grimm, D.A., Mitra, S., 2003. Pharmaceuticals and Personal Care Products (Ppcps) in Surface and Treated Waters of Louisiana, Usa and Ontario, Canada. Science of The Total Environment, 311(13): 135-149.

9. Ternes, T.A., Meisenheimer, M., Mcdowell, D., Sacher, F., Brauch, H.J., Haist-Gulde, B., Preuss, G., Wilme, U. Zulei-Seibert, N., 2002. Removal of Pharmaceuticals During Drinking Water Treatment. Environmental Science and Technology, 36(17): 3855-3863.

10. Ternes, T.A., 1998. Occurrence of Drugs in German Sewage Treatment Plants and Rivers. Water Research, 32(11): 3245-3260

11. Morse, H.N., 1978. Ueber Eine Neue Darstellengsmethode der Acetylamidophenole. Ber. Deutscher. Chem. Ges. 11, 232-233.

12. Von, Mering, J., 1893. Beitrage Zur Kenntniss der Antipyretica. Ter Monatsch. 7, 577-587.

13. İlkaya, F., Yılmaz, M.Z., Karakus, O., 2013. Parasetamol ve Siklooksijenaz Enzim İnhibisyonu, J. Exp. Clin. Med., 30: 9-14.

14. Ollers, S., Singer, H.P., Fassler, P., Muller, R.S., 2001. Simultaneous Quantification of Neutral and Acidic Pharmaceuticals and Pesticides at the Low- $\mathrm{Ng} / \mathrm{L}$ Level in Surface and Waste Water. J. Chromatogr. A 911: 225-234.

15. Koutsouba, V., Heberer, T.H., Fuhrmann, B., Schmidt-Baumler, K., Tsipi, D., Hiskia, A., 2003. Determination of Polar Pharmaceuticals in Sewage Water of Greece by Gas Chromatography-Mass Spectrometry, Chemosphere 51, 69-75.

16. Kabak, H., Basibuyuk, M., 2012. Diklofenak ve Parasetamol'ün Aktif Çamur Tarafından Adsorbsiyonu, Ekoloji 21, 85, 41-48.

17. Xiao, F., Huang, J-C. H., Zhang, B., Cui, C., 
Parasetamolün Içme Sularından Koagülasyonla Giderimi ve Sicaklı̆̆ı̆n Etkisi

2009. Effects of Low Temperature on Coagulation Kinetics and Floc Surface Morphology Using Alum, Desalination 237: 201-213.

18. Guan, D., Zhang, Z., Li, X., Lui, H., 2011. Effect of $\mathrm{Ph}$ and Temperature on Coagulation Efficiency in a North-China Water Treatment Plant, Advanced Metarials Research, 243-249: 4835-4838. 